\title{
Transformational leadership and R\&D workers' multiple commitments: Do justice and span of control matter? ${ }^{\text {ts }}$
}

\author{
Lale Gumusluoglu ${ }^{\mathrm{a}, *}$, Zahide Karakitapoğlu-Aygün ${ }^{\text {a }}$, Giles Hirst ${ }^{\mathrm{b}}$ \\ a Bilkent University, Faculty of Business Administration, Department of Management, 06800 Bilkent, Ankara, Turkey \\ ${ }^{\mathrm{b}}$ Monash University, Faculty of Business \& Economics, Department of Management, Victoria, Australia
}

\section{A R T I C L E I N F O}

Article history:

Received 1 May 2011

Received in revised form 1 December 2011

Accepted 1 February 2012

Available online 3 March 2012

\section{Keywords:}

Transformational leadership

Organizational commitment

Supervisory commitment

Organizational justice

Span of control

Social exchange

\begin{abstract}
A B S T R A C T
This study examines how transformational leaders influence research and development (R\&D) workers' commitment to their organizations and leaders. The study investigates the mediating role of organizational justice (i.e., procedural and interactional) based on social exchange theory and the moderating role of span of control in this relationship. In a sample of 445 Turkish R\&D personnel, the study finds that transformational leadership significantly influences followers' organizational commitment partially through procedural justice and their supervisory commitment partially through interactional justice. Second, the findings reveal that transformational leaders boost perceptions of procedural justice and organizational commitment when the span of control is relatively narrow. Interestingly, when the span of control is large, transformational leadership has significant positive effects on supervisory commitment, but no significant effects on organizational commitment among R\&D workers.
\end{abstract}

(c) 2012 Elsevier Inc. All rights reserved.

\section{Introduction}

Commitment is a "force that binds an individual to a course of action of relevance to one or more targets" (Meyer \& Herscovitch, 2001, p. 308). Committed employees are more likely to engage in desirable behaviors such as high performance, and motivation and to create value for their organizations (Meyer, Stanley, Herscovitch, \& Topolnytsky, 2002). Recent research claims that examining various foci of commitment such as organizational and supervisory commitments is crucial since employees do engage in separate exchange relationships with the organization to which they belong and the supervisor who is in charge of monitoring their performance (Becker, 1992; Becker, Billings, Eveleth, \& Gilbert, 1996; Vandenberghe, Bentein, \& Stinglhamber, 2004). To this end, the present study examines antecedents of organizational and supervisory commitments among R\&D workers. In doing so, specific attention to leadership is paid, as leadership is one of the most influential antecedents of commitment (Benson \& Brown, 2007; Lowe, Kroeck, \& Sivasubramaniam, 1996). Of the various leadership behaviors, transformational leadership (TL) is observed to have a positive relationship with commitment (e.g., Avolio, Zhu, Koh, \& Bhatia, 2004; Bono

\footnotetext{
is The authors acknowledge and are grateful for the comments by Ümit Berkman, Bilkent University, and S. Arzu Wasti, Sabancı University. The authors alone are responsible for all limitations and errors that may relate to the study and the paper.

* Corresponding author. Tel.: + 90312 2902319; fax: +90 3122664958.

E-mail addresses: tomruk@bilkent.edu.tr (L. Gumusluoglu),zkaygun@bilkent.edu.tr (Z. Karakitapoğlu-Aygün), giles.hirst@monash.edu (G. Hirst).
}

\& Judge, 2003; Lowe et al., 1996). Despite the suggested relevance of TL to managing knowledge work, creativity and innovation in the literature (Garcia-Morales et al., 2012; Keller, 1992), how TL affects commitment within the R\&D context is not studied.

R\&D workers, who are a sub-set of the broader category of knowledge workers, have different characteristics and value systems than traditional workers carrying out routine tasks (Drucker, 1999). These workers tend to be found in sectors which are characterized by innovation and knowledge creation, and include complex, uncertain and dynamic tasks (Morhman, Cohen, \& Morhman, 1995). Being a critical source of competitive advantage to organizations, these employees, who are short in supply, have many alternatives in the market (Flood, Turner, Ramamorthy, \& Pearson, 2001). Thus, keeping them as human resources committed to their organizations and leaders is critical. Despite their increasing importance to organizations and economies, little is known about the antecedents of organizational and supervisory commitments among R\&D workers (Benson \& Brown, 2007).

The primary aim of the current study is to examine the direct and indirect effects of TL on commitment to multiple foci among R\&D workers. As mentioned in the next sections, in spite of studies interested in the direct effects of TL on followers' commitment, research investigating the processes in those relationships is scant (Avolio et al., 2004; Bono \& Judge, 2003). The present research aims to open this black box (Jung \& Avolio, 2000) to examine the processes by which transformational leaders exert influence on followers' commitment. While trying to understand these mediating processes, the present study relies on social exchange theory, which forms a basis for 
theoretical perspectives in organizational behavior such as organizational justice. Indeed, previous research points out the importance of organizational justice as an antecedent of commitment, especially for knowledge workers (Flood et al., 2001; Thompson \& Heron, 2005). Accordingly, the quality of employee commitment is dependent on perceived interpersonal treatment and fairness of the organizational policies. When employees perceive that they are treated fairly in the organization, they reciprocate by higher levels of commitment in return. Hence, organizational justice (i.e., procedural and interactional) is proposed as a mechanism through which TL influences multiple commitments among R\&D workers.

The secondary aim of the study is to examine the moderating role of organizational context (i.e. span of control) in the above-mentioned mediating processes between TL and commitment to multiple foci. Since leader-follower relationship does not occur in a vacuum, the context in which leadership is enacted should be studied as an important contextual variable of leadership effectiveness, especially in enhancing the levels of commitment among the followers (Mowday, Porter, \& Steers, 1982; Porter \& McLaughlin, 2006). Even if managers possess the desired leadership style, organizational context, namely span of control in the present study, may interfere with their ability to influence desirable outcomes for their subordinates (Antonakis \& Atwater, 2002) such as increasing their commitment. In other words, span of control may shape the social-exchange relationships between the employee and the leader/organization and the resulting commitments to these targets. For example, the social exchange between the leader and his/her followers may become less engaging when s/he has a large span of control as compared to a narrow span of control. Thus, studying how span of control moderates leader effectiveness seems to be essential for a better understanding of the leadership phenomenon, particularly as this variable directly impacts on how organizations are designed.

Overall, this research makes the following contributions. Based on social exchange theory, the present paper attempts to integrate leadership, justice and commitment literatures. This approach illustrates that TL enhances follower commitment through organizational justice. A key contribution is that different aspects of justice, namely procedural and interactional justice, are proposed and tested for their influences on commitment to the organization and the leader, respectively. Furthermore, as the social exchange between leaders and followers may become less engaging in larger groups, the current study examines the moderating role of increased span of control. This approach sheds new light on how organizational design can influence followers' experience of leadership processes. In the next section, the theoretical background and hypotheses of the study are presented.

\section{Theoretical background and hypotheses}

\subsection{Transformational leadership}

According to the multi-factor leadership model (Bass \& Avolio, 1995), TL has four components: charismatic role modeling, individualized consideration, inspirational motivation and intellectual stimulation. By charisma, the leader instills admiration, respect and loyalty, and emphasizes the importance of having a collective sense of mission. By individualized consideration, the leader builds a oneto-one relationship with his or her followers and understands and considers their differing needs, skills and aspirations. Thus, these leaders meet the emotional needs of each employee (Bass, 1990). By inspirational motivation, the leader articulates an exciting vision of the future, shows the followers ways to achieve the goals and expresses his or her belief that they can achieve them. By intellectual stimulation, the leader broadens and elevates the interests of his or her employees and stimulates followers to think about old problems in new ways. The leader who exhibits these behaviors helps his or her followers not only exceed their initial performance expectations, but can also change their attitudes based on the strong emotional attachment he or she builds with them (Bass, 1995).

Many previous studies illustrate a strong direct link between TL and organizational commitment (Avolio et al., 2004; Bono \& Judge, 2003; Walumbwa \& Lawler, 2003; Walumbwa, Orwa, Wang, \& Lawler, 2005). They state that followers working with such leaders sacrifice their individual self-interests for the collective interests of their group when their leaders point to a collective sense of mission. When leaders pay attention to followers' development and intellectually stimulate and inspire them by a compelling vision, followers are more likely to be committed to the long-term goals of their organizations. Similarly, leaders who are genuinely interested in the welfare of their followers and maintain personalized relationships with them are likely to enhance supervisory commitment in their followers. Thus, the present study proposes that TL has direct effects on multiple commitments of R\&D workers, as well as indirect effects through the mediating role of organizational justice. Since the direct effects of TL on commitment are well-established in the literature, the focus of the present study is on the indirect effects, as mentioned below.

\subsection{Social exchange theory}

Social exchange is defined as "subjective, relationship-oriented interactions between employers and employees characterized by an exchange of socio-emotional benefits, ... a long-term focus [and] ... open-ended commitments" (Lavelle, Rupp, \& Brockner, 2007, p.845). In the literature, this framework is proposed mainly for understanding the leader-follower relationship (Bass, 1990) and the determinants of commitment (Mowday et al., 1982). A positive or negative exchange relationship with a person or entity (i.e., the leader and the organization) may affect employees' attitudes and feelings such as commitment to these targets (Brown, 1996). Previous research examines organizational justice as one important antecedent of commitment within this exchange framework and suggests that fair exchange is a sub-domain of social exchange theory (Settoon, Bennett, \& Liden, 1996; Thompson \& Heron, 2005). Such studies show that employees are not only interested in rewards, but also in how those rewards and outcomes are distributed (Greenberg, 1995). For example, procedural justice represents perceived fairness of the system such as procedures used for outcome and resource allocation (Leventhal, 1980; Lind \& Tyler, 1988; Moorman, 1991). In addition, interactional justice includes the interpersonal treatment by and fairness of the supervisor (Bies \& Moag, 1986; Cropanzano, Prehar, \& Chen, 2002; Masterson, Lewis-Mcclear, Goldman, \& Tylor, 2000; Moorman, 1991). Social exchange theory suggests that employees respond differently when they perceive unfairness in formal procedures or interpersonal treatment (Cropanzano et al., 2002; Masterson et al., 2000). Accordingly, because formal procedures represent the way the organization allocates resources; procedural justice tends to correlate highly with organization-related attitudes and behaviors. As interactional justice relates to the behaviors of the person carrying out the interpersonal treatment, this type of justice tends to be correlated with leader-related attitudes and behaviors. In other words, the source of procedural justice is the organization, while the source of interactional justice is the leader. Thus, procedural justice is expected to associate with organizational commitment and interactional justice with supervisory commitment in the present study, as discussed further in the next sections.

\subsection{The mediating role of procedural justice}

Procedural justice includes evaluation of organizational processes such as accurate information gathering for decision making, representation of those concerned with the decision making process, consistency of patterns and criteria for decision making, the possibility 
to modify and reverse decisions when new information is available and bias suppression in decision-making processes. The fairness in these processes can be of great concern for R\&D workers since they create and share knowledge only when they trust the system, as suggested by Kim and Mauborgne (1997). These authors argue that, first, engaging or involving these workers in the decisions that affect them by asking for their input tends to result in better decisions and greater commitment on the part of these workers. Second, explaining why final decisions are made "allows employees to trust managers' intentions even if their own ideas have been rejected" (p.69). Third, clarifying the expectations and stating clearly the new rules of the game allow workers to know by what standards they will be evaluated and help them focus on the job at hand. Within the social exchange framework, when workers perceive that the process is fair, they will trust the system, believe that the organization values their contributions and cares about their welfare, and consequently, reciprocate by being more committed to their organizations.

Yet, how can leaders foster the procedural justice perceptions of their followers? Leaders have a special role in implementing organizational procedures. They are the agents who enforce organizational policies and who are responsible for delivering organizational justice (Naumann \& Bennett, 2000). In other words, being the key representatives of the organizational justice processes, leaders influence the meaning followers attribute to organizational practices. Actually, TL behaviors seem to be highly relevant in fostering followers' perceptions of procedural justice. One explanation for this relationship may be that TL and procedural justice philosophies share a common concern for the collective welfare of the organization (Pillai, Scandura, \& Williams, 1999). Articulation of a vision and a collective sense of mission by transformational leaders communicate the policies of the organization in a way that takes the employees into account and therefore, create a culture of justice among employees.

Similarly, procedural justice increases employees' control over decisions and enhances group solidarity in the long run (Greenberg, 1995). This view of procedural justice enhances feelings of collective welfare among followers, which is the main concern of transformational leaders. Such leaders also consider the moral and ethical consequences of decisions (Bass, 1990), and thus are likely to explain the reasons behind organizational decisions, to question the appropriateness of evaluative criteria and the accuracy of the information used in organizational decisions and to enhance their employees' voices. On the basis of social-exchange framework, R\&D workers, in return, are likely to respond by being more committed to their organizations. In other words, although the leaders play a bridge role between the organization and the followers, the main source of procedural justice and the target to which the employees will be committed to is the organization.

H1. Perceived procedural justice partially mediates the relationship between TL and R\&D workers' commitment to the organization.

\subsection{The mediating role of interactional justice}

As mentioned above, interactional justice refers to the fairness of and interpersonal treatment by the leader. As compared to procedural justice, interactional justice includes less formalized aspects of interaction (DeConinck, 2010). Interactional justice specifically includes the degrees of honesty, sensitivity and respect shown by the leader during the interaction (Colquitt, Conlon, Wesson, Porter, \& $\mathrm{Ng}, 2001)$. In other words, this type of justice refers to "the human side of organizational practices, that is, the way the management is behaving toward the recipient of justice" (Cohen-Charash \& Spector, 2001, p. 281). On the basis of social exchange theory, interactional justice affects the extent to which workers have positive work experiences with their leaders, because those perceptions are based on the consistency and truthfulness of the leaders themselves. Thus, these workers tend to reciprocate with higher levels of commitment to their leaders.

Research on knowledge workers illustrates that autonomy, task discretion and strong professional standards require participative and supportive managerial styles. First, relationships with leaders are reported to be a significant domain of effective management for this group of workers as compared to traditional workers (Benson \& Brown, 2007). Knowledge workers expect their leaders to respect their know-how and allow them the discretion to actualize their potential, develop their personal and intellectual capacity and achieve their career goals. Second, relationships between knowledge workers and their leaders are positively associated with knowledge creation and innovative behavior among this highly qualified group (Tierney, Farmer, \& Graen, 1999). Lack of fair treatment by their leaders may have detrimental effects on their job performance since these workers have a significant drive for achievement and personal growth compared with traditional workers (Despres \& Hiltrop, 1995; Rosenbaum, 1991). Therefore, the present study argues that fair interpersonal treatment is especially important in shaping R\&D worker's attitudes toward their leaders.

TL behaviors seem to be highly relevant in cultivating interactional justice perceptions among followers. First, transformational leaders treat their subordinates as individuals rather than as members of a group, and address their differing needs and abilities through individualized consideration in a truthful and fair manner. As such, these leaders build active and emotional relationships with their followers (Bass, 1990). Hence, such considerate leaders are well expected to show polite treatment, respect, and sensitivity to individual needs of their followers. Second, these leaders demonstrate high standards of moral conduct (Avolio, 1999) and emphasize ethical components of leadership such as concern for others and value-based leadership (Trevino, Brown, \& Hartman, 2003). Such ethical behaviors by transformational leaders are conducive to the fair and equitable treatment of their employees, which in turn are likely to communicate respect and to enhance followers' self-esteem (Sousa \& Vala, 2002). Employees are more likely to perceive higher levels of interactional justice under this leadership, and based on the social exchange framework, show higher levels of commitment to their leaders.

H2. Perceived interactional justice partially mediates the relationship between TL and R\&D workers' commitment to their leaders.

\subsection{The moderating role of span of control}

Organizational context is a major variable influencing behavior at the workplace (Johns, 2006) and leadership behavior and outcomes, specifically (Pawar \& Eastman, 1997; Porter \& McLaughlin, 2006). Johns (2006) defines context as "situational opportunities and constraints that affect the occurrence and meaning of organizational behavior as well as functional relationships between variables" (p.386). Accordingly, context can interact with other personal and dyadic variables and act as a moderating factor in individual and group behavior. In the field of leadership, the calls to study leader-context interplay are increasing in recent years (Porter \& McLaughlin, 2006). Specifically in the TL literature, Pawar and Eastman (1997) argue that organizational context influences organizational receptivity (i.e., organizational members' responsiveness) to TL and studies should incorporate the effects of different contextual factors in order to better grasp this leadership style. The aim of the present study is to address these gaps and shed light on the intricacies of leadership by studying span of control as a contextual variable.

Studies examining leadership-context interaction mostly focus on leader distance (Antonakis \& Atwater, 2002) which is defined as "a multidimensional construct that describes the psychological, structural and functional separation, disparity, or discord between a supervisor and a subordinate" (Napier \& Ferris, 1993, p.326). Such studies 
of leader distance consider span of control as one aspect of structural distance. Accordingly, the present study adopts a narrower definition of structural distance as the span of control, which is defined as the number of followers reporting formally and directly to a particular leader (Schyns, Maslyn, \& Weibler, 2010).

According to Napier and Ferris (1993), who consider span of control as a leader distance factor, the amount of attention, support and feedback given to each follower may decrease as the number of subordinates supervised increases. When the span of control is small, leaders can be perceived to be more effective. One reason for this may be that when the number of followers to supervise increases, leaders may have some resource constraints. For example, time to interact with each of the followers may be limited. Dansereau, Graen, and Haga (1975) argue that leaders have limited resources of time and energy which may prevent them to maintain personalized relationships when they are supervising a large group of subordinates.

Another factor that may positively contribute to leaders' effectiveness in a smaller span of control is the proximity and the contact between the leader and his or her followers. For example, Judge and Ferris (1993) illustrate that leader-follower contact is relatively limited when the span of control is large. Similarly, Bass (1990) argues that followers can interact more and develop a higher quality of communication with physically close leaders, which is more likely to occur in a smaller span of control. Consistent with these findings, Schyns et al. (2010) suggest that for employees to exert extra effort and show liking of their leaders, the leader-follower relationship should be close. In other words, leaders need to build and maintain day-to-day interactions with their followers, which is easier to do when the number of followers is relatively small (Schyns, Paul, Mohr, \& Blank, 2005).

Similar contentions exist in the TL research. In one such study, Howell and Hall-Merenda (1999) show that TL predicts significantly higher follower performance in close situations. These proximally close situations require one-to-one relationships with employees, which often happen when the number of subordinates per leader is relatively few. In a similar vein, Howell, Neufeld, and Avolio (2005) report that when the leader-follower distance is close, the relationships between TL and unit performance get stronger. Similarly, Shamir (1995) in a qualitative study illustrates that close leaders tend to have positive effects on followers' motivation, and generate positive affect and enhanced level of follower identification and emulation. Supporting these findings, Cole, Bruch, and Shamir (2009) argue that close leaders are more likely to transmit their belief systems to subordinates through behavioral role modeling and guidance in the form of direct feedback.

Based on these observations, one can argue that a transformational leader with a narrower span of control may be more effective, because such a leader is more likely to build close contact with his or her followers, to pay more attention to their individual needs and to form and maintain more personalized interactions with the followers. In such a context, the leaders' honesty, kindness and reliability can be directly manifested by the leader and evaluated by the followers. In such conditions, availability, fairness and promise fulfillment by the leader are likely to result in higher levels of trust and attachment to the leader (Shamir, 1995). Furthermore, close leaders have more chances to show their recognition and approval, and demonstrate their concern for the well-being of their followers. Consequently, followers are expected to develop higher levels of commitment to such leaders.

Similarly, when leaders are supervising a low number of followers, they may find more opportunities to communicate the organizational rules and influence the meaning followers attribute to organizational practices. In a smaller span of control, leaders may have better chances to engage their followers in decision-making processes, explain organizational decisions to them and clarify what the organization expects from them since they can spend more time with and energy on them. In such a context, leaders may act as a bridge between the organizational authorities and the followers, generate more support for the organization's vision and goals and develop followers' commitment to the organization. Indeed, transformational leaders are better able to communicate an organization's vision where the number of subordinates to supervise is few rather than large (Berson, Shamir, Avolio, \& Popper, 2001).

In all, a smaller span of control can make TL behaviors more salient as in such a context leaders may be in a better position to build a sense of community that consists of a family feeling, trust and caring, and to touch and enhance their followers' organizational justice perceptions. When leaders establish such positive work experiences with their followers, followers will respond by heightened levels of commitment to their organizations and leaders.

H3. Span of control moderates the relationships between TL, organizational justice and R\&D workers' organizational and supervisory commitments such that the relationships will be stronger when the span of control is smaller rather than larger.

\section{Method}

\subsection{Sample}

The total survey sample includes 445 (319 males, 124 females, two unidentified) Turkish R\&D workers employed by 65 hightechnology companies located in the technoparks of two universities in Ankara: Bilkent University and Middle East Technical University (METU). These firms mainly operate in R\&D in areas such as information and communication technologies, electronics and biotechnology. Among the participants, 261 (192 males, 68 females, one unidentified) work in project teams that have a narrower span of control (four to eight members in the sample) and 184 (127 males, 56 females, one unidentified) work in teams that have a wider span of control (10 to 22 members in the sample). The average age of the participants is 28 years (27.6). Of the sample, $73.1 \%$ have university or post-graduate degrees. The average job and company tenures are 4.1 and 2.2 years, respectively. The average tenure with the leader is 1.8 years ( 1.4 for large and 2.2 for small span of control).

\subsection{Procedure and measures}

First, the general managers of the two technoparks are contacted. After receiving a list of firms operating in each technopark, the managers of the R\&D departments of the firms are contacted by telephone. Then, R\&D personnel in each firm are asked to fill out the survey, which is presented in envelopes to assure confidentiality. All respondents fill out the survey in their offices and are assured that their responses will be confidential.

The Turkish version of the scales is checked through back translations. Native speakers of English and Turkish also checked the scales for wording, accuracy and clarity of items. Except for TL, which is rated on a frequency scale, all items in the study are rated on a five-point scale ranging from 1 ("Strongly disagree") to 5 ("Strongly agree").

\subsubsection{Commitment}

Affective commitment to the organization is measured with an eight-item scale, which has been tested in the Turkish context in previous studies (Wasti, 2000). Wasti reports acceptable reliabilities for this measure, which includes both emic and etic items (Meyer, Allen, \& Smith, 1993). Sample items include "I really feel as if this organization's problems are my own," and "I do not feel a strong sense of belonging to my organization" (reverse-coded). Affective commitment to the supervisor is measured with Vandenberghe et al.'s (2004) six-item scale. Sample items include "I feel proud to 
work with my supervisor" and "I feel little admiration for my supervisor" (reverse-coded). Confirmatory factor analysis is conducted to test for the psychometric properties of the two scales. For these purposes, items representing organizational commitment are forced to load under the first dimension and items on supervisory commitment to the second dimension. Two items from the organizational commitment subscale have low factor loadings in the preliminary analysis, therefore, those two problematic items are omitted. The resulting two-factor solution yields an acceptable fit: $\chi^{2}(52, \quad \mathrm{~N}=445)$ $=320.91, \mathrm{RMSR}=.05, \mathrm{CFI}=.96, \mathrm{NNFI}=.95$. The comparison of this 2-factor model with one-factor solution (where all items are loaded on one factor) confirms the superiority of the 2-factor solution, $\Delta \chi^{2}=710.14, p<.001$.

\subsubsection{Justice}

Procedural justice is measured with six items (Lamertz, 2002), such as "My company uses procedures designed to collect accurate information necessary for making decisions" and "My company uses procedures designed to provide opportunities to appeal or challenge the decision." Interactional justice scale includes six items from Moorman (1991), such as "My supervisor was able to suppress personal biases," "My supervisor provided me with timely feedback about the decisions and their implications." Confirmatory factor analysis is conducted to see if the items load on two distinct factors of procedural and interactional justice. Initial analysis shows that two items from the interactional justice scale have poor psychometric properties, therefore, these two items are omitted. The results reveal an adequate fit: $\chi^{2}(33, \mathrm{~N}=445)=190.90, \mathrm{RMSR}=.04, \mathrm{CFI}=.96$, $\mathrm{NNFI}=.95$. This 2 -factor model is compared with one-factor solution (where all items are loaded on one factor). The results yield that a 2factor solution has a better fit than the one-factor solution, $\Delta \chi^{2}=283.88, p<.001$.

\subsubsection{Transformational leadership}

Leadership style is measured using 20 items from the Turkish version of the copyrighted Multi-Factor Leadership Questionnaire (MLQForm 5X: Bass \& Avolio, 1995). Participants are asked to judge how frequently their immediate project leader engage in TL behaviors on a five-point Likert scale: 1 ("Not at all") and 5 ("Frequently, if not always"). Sample items include "Articulates a compelling vision of the future," "Treats me as an individual rather than as a member of the group" and "Gets me to look at problems from many different angles." Although TL is conceptualized as four distinct domains in the literature, the present study does not make such a distinction among the components of TL. Recent research shows that these four components are highly correlated and constitute the higher-order construct of TL, resulting in more parsimony (Avolio, Bass, \& Jung, 1999). Hence, onefactor confirmatory factor analysis is conducted. In preliminary analyses, items with relatively low factor loadings are omitted, resulting in 14 reliable items. Omitted items mostly represent attributed idealized influence. The final model results in an adequate fit: $\chi^{2}$ (74, $\mathrm{N}=445)=494.85$, RMSR $=.047 \mathrm{CFI}=.97, \mathrm{NNFI}=.96$. In addition, TL in the present study is treated as an individual-level variable as leaders may not behave in a uniform manner across followers and situations (Walumbwa, Wang, Lawler, \& Shi, 2004). Group-level analysis "has the potential of washing out important relationships that might exist, especially when dealing with individual perceptions" (Walumbwa et al., 2005, p. 245). Thus, leadership is considered at the individual level to capture followers' individual differences.

\subsubsection{Control variables}

As suggested by Spector and Brannick (2010), authors should provide theoretical justifications for the inclusion of control variables in their research. Regarding the commitment literature, researchers suggest that antecedents of commitment generally fall into four categories: demographic characteristics (age, gender, tenure, etc.), structural characteristics, job-related characteristics and work experiences (Meyer \& Allen, 1991; Mowday et al., 1982). For example, the positive relation between tenure and commitment may be due to the tenure-related differences in job-status or, alternatively, due to attempts on the part of senior employees to justify their having remained with the company for so many years.

Justice literature also argues that characteristics of the perceiver can affect his/her justice perceptions. In their meta-analytical review of the role of justice in organizations, however, Cohen-Charash and Spector (2001), find less strong relationships between demographic characteristics of the perceivers and justice perceptions. In spite of this controversy in the justice literature, gender, age, company and job tenure as well as tenure with the leader are included as control variables in the present study since the dependent variable is commitment.

\section{Results}

Table 1 shows the means, standard deviations, correlations and alpha values for the main study and control variables. Among the control variables, only tenure with the leader has significant correlations with the main study variables. Hence, the effects of tenure with the leader are controlled for in further analyses. The initial analyses on correlations reveal that TL shows moderate-to-high correlations with the mediating and outcome variables. In addition, organizational commitment and supervisory commitment are moderately related to each other. As hypothesized, procedural justice shows the highest correlation with organizational commitment and interactional justice with supervisory commitment. As can be seen from Table 1, the correlations between $\mathrm{TL}$, interactional justice and commitment to the leader are relatively high (between 0.67 and 0.76 ). To check for a potential multicollinearity problem, variance inflation factor (VIF) scores are computed. All of the conditioning indexes are below 30, and all of the VIF values are below three, suggesting that multicollinearity is not evident in the data set.

\subsection{The test of mediation effects}

Structural equation modeling (SEM) is used to test the proposed hypotheses. Before conducting the SEM analyses, three parcels are formed for each of the variables (except for TL and interactional justice), because the use of parcels reduces the number of variables in a model and increases the reliability of indicators. Four parcels are created for TL in accordance with the four dimensions suggested by Bass and Avolio (1995). For interactional justice, two indicators are created since the scale includes only four items. The LISREL 8.80 program (Jöreskog and Sörbom, 1993) and maximum likelihood estimation are used for the analyses. The $\chi^{2} / d f$ ratio, the root mean square

Table 1

Means, standard deviations, reliabilities and zero-order correlations $(\mathrm{N}=445)$.

\begin{tabular}{llllllll}
\hline & $\mathrm{M}$ & $\mathrm{SD}$ & 1 & 2 & 3 & 4 & 5 \\
\hline 1. TL & 3.9 & 0.62 & $(0.93)$ & & & & \\
2. Procedural justice & 3.8 & $\mathbf{0 . 6 5}$ & $\mathbf{0 . 4 7}$ & $(0.86)$ & & & \\
$\begin{array}{l}\text { 3. Interactional justice } \\
\text { 4. Commitment to }\end{array}$ & 4.0 & $\mathbf{0 . 6 8}$ & $\mathbf{0 . 7 6}$ & $\mathbf{0 . 4 7}$ & $(0.81)$ & & \\
$\quad$ the organization & & $\mathbf{0 . 6 5}$ & $\mathbf{0 . 4 2}$ & $\mathbf{0 . 5 0}$ & $\mathbf{0 . 3 3}$ & $(0.78)$ & \\
5. Commitment to & 4.1 & $\mathbf{0 . 6 5}$ & $\mathbf{0 . 7 2}$ & $\mathbf{0 . 3 9}$ & $\mathbf{0 . 6 7}$ & $\mathbf{0 . 4 9}$ & $(0.90)$ \\
$\quad$ the leader & & & & & & & \\
6. Age & 27.6 & 4.86 & 0.00 & -0.05 & -0.04 & 0.05 & 0.02 \\
7. Gender & - & - & 0.01 & -0.05 & -0.09 & 0.00 & 0.00 \\
8. Leader tenure & 1.8 & 1.87 & $\mathbf{0 . 1 0}$ & $\mathbf{0 . 1 0}$ & -0.01 & $\mathbf{0 . 1 6}$ & $\mathbf{0 . 1 2}$ \\
9. Company tenure & 2.2 & 2.26 & 0.06 & -0.01 & -0.03 & 0.07 & 0.04 \\
10. Job tenure & 4.1 & 4.37 & -.03 & -.04 & -.07 & .07 & .01 \\
\hline
\end{tabular}

Note. All of the correlations (in bold) among the main study variables are significant at the .001 level. Correlations between leader tenure and main study variables are significant at .05. Reliabilities are reported in parentheses. 
residual (RMSR) and the non-normed fit index (NNFI) are used to evaluate the overall fit of the models. Generally, NNFI above .90, RMSR below .05 , and $\chi^{2} / d f$ below 3 indicate a reasonable fit (Kline, 1998).

First, a measurement model is estimated to test the properties of the latent variables. Fit indices for the measurement model are acceptable: $\chi^{2}(94, \mathrm{~N}=430)=274.11, \chi^{2} / d f=2.91, \mathrm{RMSR}=.038$, $\mathrm{NNFI}=.9$. Then, a structural model is estimated to test the partial mediation hypotheses for commitment foci. Fit indices for this model are satisfactory: $\chi^{2}(96, \mathrm{~N}=430)=278.10, \chi^{2} / d f=2.89, \mathrm{RMSR}=.04$, $\mathrm{NNFI}=.95$. However, to illustrate the superiority of this model, two alternative models are tested, one testing full mediation (Alternative Model 1: Direct paths from TL to two commitment foci are dropped) and another testing no-mediation (Alternative Model 2: Paths from interactional and procedural justice to commitment foci are not estimated). Results indicate that fit indices for Alternative Model 1 and Alternative Model 2 are $\chi^{2}(98, \mathrm{~N}=430)=307.20, \chi^{2} / \mathrm{df}=3.13$, RMSR $=.05, \mathrm{NNFI}=.94$ and $\chi^{2}(98, \mathrm{~N}=430)=360.61, \chi^{2} / d f=3.68$, $\mathrm{RMSR}=.07, \mathrm{NNFI}=.93$, respectively. The comparison of the hypothesized model with Alternative Model 1 reveals that the former has a better fit: $\Delta \chi^{2}=29.1, \Delta d f=2, p>0.001$. Similarly, the comparison with Alternative Model 2 assures the superiority of the hypothesized model: $\Delta \chi^{2}=82.51, \Delta d f=2, p>0.001$. The consistent Akaike's information criterion (CAIC) which is mostly used in alternative model comparisons also supports the superiority of the hypothesized model which reveals the lowest score (Homburg \& Pflesser, 2000). The CAIC values for the hypothesized and Alternative Models 1 and 2 are $566.10,577.47$ and 615.93 , respectively. The results of this hypothesized model are shown in Fig. 1. All factor loadings for each scale indicator, the error variances and the path coefficients between the latent constructs are significant at a 0.05 significance level. As can be seen from Fig. 1, first, procedural justice partially mediates the relationship between TL and commitment to the organization. Second, interactional justice partially mediates the association between TL and commitment to the leader. In summary, the results support the first two hypotheses, suggesting that interactional justice and procedural justice partially mediate the relationship between TL, and commitment to the leader and organization, respectively.

\subsection{The test of moderation effects}

The moderating role of span of control is tested through multigroup analysis, which tests whether or not a model has the same parameter values in two different groups. First, the measurement model and then the structural models across the two groups (i.e., large versus small span of control) are tested. As suggested by Kline (1998), covariance matrices are used and only factor loadings and path coefficients are constrained, but not the covariances and error variances. While testing for the moderation effects, equality constraints on each path across the two groups are set step by step. The fit of the models are evaluated by comparing them to the model in which factor loadings are constrained to be equal across the two groups. Then, chi-square changes are computed by subtracting the smaller $\chi^{2}$ and degrees of freedom from the larger ones. Significant $\chi^{2}$ changes are expected to illustrate moderation effects.

As mentioned earlier, before testing the proposed model, a measurement model is specified to assess the measurement properties of all latent variables (i.e., TL; interactional and procedural justice; and two commitment foci) across the two groups. All the factor loadings for each scale indicator and all the error variances are significant at 0.05 , and the measurement model yields an acceptable level of fit across the two groups (Table 2).

The model with no equality constraints on either the measurement or the structural model yields an acceptable level of fit. All the factor loadings for each scale indicator and all the error variances are significant at 0.05 . Next, an equality constraint is imposed on the factor loadings of the measurement model. This procedure does not result in a significant $\chi^{2}$ change, suggesting measurement invariance in factor loadings across the two groups, which is the first requirement to conduct multi-group analyses. This factor loading invariance indicates that obtained ratings can be meaningfully compared across the two groups.

Then, step by step, equality constraints on each path in the structural model are imposed to see the moderating effects of span of control (see Tables 2 and 3). Moderation effects are detected in two paths only (see also Fig. 1). First, the path from TL to procedural justice is moderated by span of control. More specifically, although the path coefficients are significant in both groups, the coefficient is stronger when the span of control is small rather than large. Second, the path from TL to organizational commitment is significantly different in the two groups, the path being statistically significant only for the small group. However, the other path coefficients are quite similar across the two groups, as seen in Table 3.

\section{Discussion}

The major aim of the present study is to investigate how leaders can enhance the commitments of R\&D workers. The findings show

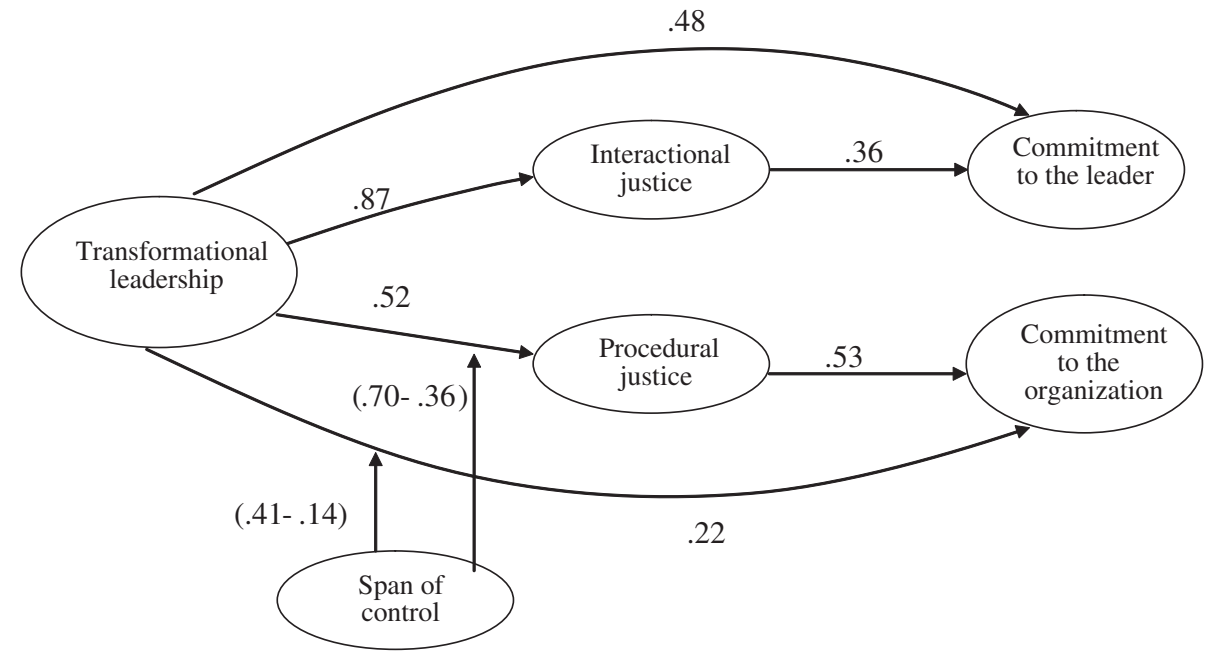

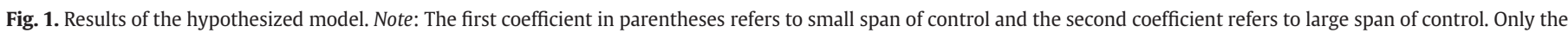
path coefficient of .14 (TL-commitment to the organization path for the large span of control) is not significant. 
Table 2

Results of the multi-group analyses.

\begin{tabular}{llllllll}
\hline & $\chi^{2}$ & $d f$ & $\chi^{2} / d f$ & $\Delta \chi^{2}$ & $\Delta d f$ & RMSR & NNFI \\
\hline Measurement model & 406.37 & 168 & 2.42 & - & - & 0.058 & 0.97 \\
Hypothesized model & 367.07 & 164 & 2.24 & - & - & 0.030 & 0.98 \\
Model 1 & 377.79 & 174 & 2.17 & 10.72 & 10 & 0.037 & 0.98 \\
Model 2 & 391.13 & 175 & 2.23 & $13.34^{* * *}$ & 1 & 0.062 & 0.98 \\
Model 3 & 377.96 & 175 & 2.16 & .17 & 1 & 0.037 & 0.98 \\
Model 4 & 378.74 & 175 & 2.16 & .95 & 1 & 0.037 & 0.98 \\
Model 5 & 378.06 & 175 & 2.16 & .27 & 1 & 0.037 & 0.98 \\
Model 6 & 383.46 & 175 & 2.19 & $5.67^{*}$ & 1 & 0.043 & 0.98 \\
Model 7 & 378.15 & 175 & 2.16 & .36 & 1 & 0.037 & 0.98
\end{tabular}

Note: Model 1: factor loadings are constrained to be equal across the two groups, Model 2: the path from TL to procedural justice is constrained, Model 3: the path from TL to interactional justice is constrained, Model 4: the path from procedural justice to organizational commitment is constrained, Model 5: the path from interactional justice to commitment to the leader is constrained, Model 6: the path from TL to organizational commitment is constrained, and Model 7: the path from TL to commitment to the leader is constrained.

$* p<0.05$.

$* * * \quad p<0.001$.

that $\mathrm{TL}$ is an appropriate style for enhancing the commitments of this professional group to their organizations and to their leaders. Supporting the social exchange framework, the present study identifies organizational justice as a critical process through which transformational leaders influence their followers' commitment. More specifically, the results reveal partial mediation effects of procedural justice and interactional justice in the relationships between TL and followers' organizational and supervisory commitment, respectively. Furthermore, the moderating role of span of control is identified on the relationships between TL-procedural justice and TL-organizational commitment, whereby transformational leaders boost perceptions of procedural justice and organizational commitment among their followers when the span of control is small. In the next sections, the direct and indirect effects of TL on multiple commitments and the moderating role of span of control on these relationships are discussed.

As expected, TL has a direct effect on organizational commitment, which is in line with previous research (Avolio et al., 2004; Bono \& Judge, 2003; Walumbwa \& Lawler, 2003; Walumbwa et al., 2005). However, as further explained in The test of moderation effects section, this direct effect is significant only when the span of control of the leader is narrow. Transformational leaders enhance their followers' commitment to the organization through emphasizing goal accomplishment, showing personalized attention to followers' needs and creating a high level of commitment to the common vision and long-term goals of their organizations (Avolio et al., 2004). Second, and more important, supporting the first hypothesis, procedural justice emerges as an important mechanism though which these leaders may influence their followers' organizational commitment. Transformational leaders involve their followers in the decisions that affect them, state new rules and policies clearly, critically evaluate decisions and the accuracy of the information used in those decisions. In other

Table 3

Results of the moderation analyses: path coefficients for small and large spans of control.

\begin{tabular}{|c|c|c|c|}
\hline & $\begin{array}{l}\text { Small span } \\
\text { of control }\end{array}$ & $\begin{array}{l}\text { Large span } \\
\text { of control }\end{array}$ & $p\left(\Delta \chi^{2}\right)$ \\
\hline TL-interactional justice & 0.88 & 0.91 & ns \\
\hline TL-procedural justice & 0.70 & 0.36 & 0.001 \\
\hline TL-commitment to the organization & 0.41 & 0.14 & 0.02 \\
\hline TL-commitment to the leader & 0.31 & 0.28 & ns \\
\hline $\begin{array}{l}\text { Procedural justice-commitment to } \\
\text { the organization }\end{array}$ & 0.42 & 0.52 & ns \\
\hline $\begin{array}{l}\text { Interactional justice-commitment to } \\
\text { the leader }\end{array}$ & 0.51 & 0.49 & ns \\
\hline
\end{tabular}

words, by using the principles of engagement, explanation and clarification of the expectations, these leaders tend to enhance the perceptions of fair processes at the workplace. Indeed, such use of fair procedures by leaders conveys messages to employees that management is interested in their welfare, respects their rights and that employees will be treated fairly in the long term (Dayan, Benedetto, \& Colak, 2009). Based on the social exchange framework, followers of such leaders perceive that policies and procedures are fair at the systemic level and, in return, may reciprocate with higher levels of organizational commitment. Such perceptions of a fair environment are especially critical for R\&D workers, who need to trust the system in order to create and share knowledge (Flood et al., 2001; Kim \& Mauborgne, 1997). Since these workers need a great deal of autonomy in their work environment and emphasize professional excellence (Kinnear \& Sutherland, 2000), they are more likely to challenge decisions affecting them, such as those related to their professional achievement and recognition. They expect their leaders to provide them with opportunities to collect accurate information necessary for making decisions, to hear the concerns of all those affected by the decisions and to appeal or reject decisions. In case of an unfair rule or decision at the organizational level, such leaders can play a more active role and advocate in favor of their workers to protect their rights and assure the harmony of their group.

In line with the expectations of the study, significant direct effect of TL is identified also on commitment to the leader. When transformational leaders go beyond self-interest for the good of the group, their followers display respect, trust, pride and confidence in them (Walumbwa et al., 2005). As mentioned earlier, these leaders also attend to the differential development needs of their followers and show sensitivity to their interests. As predicted by the social exchange framework, followers may develop higher levels of attachment to the enacters of such positive behaviors. This strong effect of TL on supervisory commitment can also be explained by the traditional cultural and organizational context in Turkey, which is defined as relatively collectivistic and paternalistic (Aycan, Kanungo, Mendonce, Kaicheng, \& Deller, 2000; Berkman \& Özen, 2007). In such contexts, transformational leaders may be expected to create more positive outcomes. Indeed, previous research claims that TL tends to emerge and be more effective in collectivist environments and for collectivists (Bass, 1995; Felfe, Yan, \& Six, 2008, Jung, Bass, \& Sosik, 1995; Walumbwa, Lawler, \& Avolio, 2007). Cultural values in such contexts seem to be more in line with those leaders' emphases on a collective mission and collective goals and responsibilities (Jung \& Yammarino, 2001).

In addition to this direct effect, as hypothesized $\left(\mathrm{H}_{2}\right)$, interactional justice partially mediates the relationship between TL and followers' supervisory commitment. Given that these leaders treat their followers as individuals rather than as members of a group, and consider their different needs and expectations (Bass, 1990), they are likely to treat them with dignity, respect, kindness, honesty and show concern for their opinions and rights. Such fair interpersonal treatment is especially important for R\&D workers for whom autonomy, voice and respect for their intellectual capacities are highly crucial. When leaders do not deal well with these workers' concerns about their careers or job-related issues, and show disrespect to their know-how, deception, invasion of privacy and derogatory judgments (Bies, 2001), employees may reciprocate this unfair and inconsiderate treatment by decreased supervisory commitment supporting the predictions of social exchange theory.

Another important finding of the current study is that span of control moderates the relationships between TL, and perceptions of procedural justice and organizational commitment. As hypothesized $\left(\mathrm{H}_{3}\right)$, these relationships are stronger when the span of control is smaller. These findings are consistent with the contentions that the distance between the leader and the follower is an important factor in leadership effectiveness, in general (Antonakis \& Atwater, 2002; 
Napier \& Ferris, 1993), and TL effectiveness, in particular (e.g., Avolio et al., 2004; Cole et al., 2009; Howell \& Hall-Merenda, 1999; Howell et al., 2005; Shamir, 1995). These results also imply that followers are more receptive to TL (Pawar \& Eastman, 1997) when the number of followers the leader supervises is small. Accordingly, the first moderation effect implies that transformational leaders tend to play a facilitator role in fostering a procedurally just system at the workplace when they lead smaller teams. In other words, influencing the perceived fairness of the decision-making process and the distribution system is probably easier for these leaders, when they are supervising a relatively few number of people. Leaders in such contexts are more likely to communicate organizational policies and decisions, the reasons behind them and to assure consistency of the rules in decision making. Furthermore, such leaders in these contexts have more opportunities to engage followers in decision-making processes and to make expectations clear since they likely have more time and energy to deal with each individual follower.

The second moderation effect reveals that TL is effective in enhancing the organizational commitment only when the number of subordinates is small. With a smaller span of control, leaders apparently have more chances to build a sense of community consisting of a family feeling and thus transform their followers' individual self-interests into collective interests. Such close leaders may be in a better position to communicate the organizational vision and the goals through their one-to-one interactions with their followers. As stated by Berson et al. (2001), "by providing an exciting vision that is also tied to instrumental goals and objectives, the transformational leader may be able to move even the most resistant followers toward achieving the vision" (p. 67). Hence, followers tend to work toward long-term goals and be more committed to their organizations when they work under such close leadership situations. In contrast to Avolio et al. (2004), who show that upper level leaders can create organizational commitment, this study finds that even immediate project leaders can enhance followers' organizational commitment when they are leading smaller teams. Avolio et al. (2004) argue that in a high power-distance culture, lower level leaders deal with daily routine management while higher level leaders articulate the vision throughout the organization and hence create organizational loyalty. As mentioned above, the Turkish business context is also defined as relatively collectivistic. In such a context, followers expect their leaders to form and maintain personalized relationships. When followers' immediate project leaders build one-to-one relationships (more likely to happen in smaller teams), their perceptions of a family feeling and commitment to their organization may increase.

One should note that this direct effect of TL on organizational commitment is not significant when the span of control is large. This finding challenges previous studies that show a direct effect of TL on organizational commitment and reveal a moderately strong relationship between these two variables (Avolio et al., 2004; Bono \& Judge, 2003; Walumbwa \& Lawler, 2003; Walumbwa et al., 2005). The results imply that span of control as a structural variable moderates this well-established link between TL and organizational commitment. This finding may be explained by the above-mentioned time- and energy-related constraints these leaders may face in a larger span of control; creating a family feeling and sense of belonging among his or her followers may not be possible for a leader since she or he may not maintain personalized relationships if supervising a large number of people. This leader distance may act as a barrier to organizational loyalty as leaders may be seen as less active by followers and less capable of creating a collective sense of mission and welfare.

More interestingly, while transformational leaders do not have any significant effect on organizational commitment when leading a large group of employees, they have a significant effect on supervisory commitment. That is, the present study identifies a strong TL-supervisory commitment relationship regardless of the leader's span of control. This may be explained by the salience of the commitment foci to the leadership construct. The daily behaviors of transformational leaders such as teaching and coaching, considering followers' differing skills and expectations, showing confidence in their expertise and abilities and stimulating them intellectually, are more salient and vivid to employees. Thus, these behaviors may directly boost supervisory commitment, which is a more proximal outcome of leadership. On the contrary, it is more demanding for such leaders to enhance organizational commitment among their followers, which is a more distal outcome of leadership. In that case, leaders are in an intermediary position, acting as a bridge between the followers and the organizational unit and communicating organizational issues and decisions to the followers. Playing this bridge role successfully may be much more difficult when the number of people to supervise gets larger, as mentioned before.

One consequence of the above situation, that is, when employees are committed to their leader but not necessarily to their organization, may be that they leave the company when the leader quits. This is especially noteworthy in an R\&D context since these workers are more mobile (Drucker, 1969; Flood et al., 2001). Indeed, in another project (Karakitapoğlu-Aygün \& Gumusluoglu, 2011) where R\&D workers are interviewed about TL, these workers frequently mention their commitment to such leaders and state that when those leaders change departments in a company, their team members usually follow them. Even when these leaders change employers, subordinates tend to follow them to the new location. This finding brings to mind recent discussions in the literature on the dark side of leadership, which argue that identification with the leader creates dependency, submissive loyalty and conformity, (Conger \& Kanungo, 1998; Kark, Shamir, \& Chen, 2003) and that departure of the leader may result in feelings of crisis, loss and distress (Shamir, 1991). In such cases, performance problems and turnover may be more likely following the departure of the leader. Thus, commitment of followers to their leaders but not to their organizations may result in the loss of valued professional employees, which may not only impose high recruitment, replacement and training costs, but also may decrease organizational morale, performance and effectiveness.

\section{Limitations, implications and concluding remarks}

One limitation of the current study is the use of a cross-sectional design. Although the conceptual model is tested through SEM, the relationships are associative and correlational, which do not allow for the assessment of real cause-effect relationships. Longitudinal research should be conducted to understand the processes by which transformational leaders influence the commitment levels of their followers. One may also argue that common-method variance may constitute a limitation. However, since this study is interested in the perceptions and commitments of the followers, data is collected from the followers themselves. Only for TL could data be obtained from other sources, but since the focus here is on followers' perceptions of fairness and commitment, followers rather than their colleagues or leaders are the most appropriate source through which to evaluate TL characteristics. Furthermore, future research should investigate R\&D workers' commitment to their work groups. As these workers are mostly located in teams where they are expected to share their know-how and create knowledge collectively, studying the predictors of attachment to their teams will be worthwhile. Future studies may also be interested in examining other mediators such as distributive justice, which represents the tangible outcomes of the application of procedures and other contextual moderators such as physical, social and interactional distances (Cole et al., 2009) or macro-level structural characteristics such as the hierarchy of the leader under question. For example, an interesting avenue will be to study how these distance dimensions simultaneously interact with TL to influence commitment to multiple foci. As Cole et al. 
(2009) indicate, different dimensions of distance may jointly influence the effects of leadership on various job outcomes.

The findings have several implications for leaders of project teams and human resource managers. First, the mediation-related results of the current study suggest that leaders can positively influence their subordinates' organizational commitment by increasing the perceptions of procedural justice. Hence, they should emphasize the fairness of procedures used in decision making and in the distribution system. Establishing institutional channels for employees to participate in decision-making processes and using transparent criteria in the performance evaluation and feedback systems can be some important means to this end. Second, to enhance the commitment to the leader, the leaders should interact with subordinates in a truthful and polite manner and show sensitivity to their needs and expectations. These findings imply that soft skills of project leaders should be taken into account in addition to their technical skills for effective management of R\&D workers; leading professional employees in the R\&D context needs more than technical expertise when quality and innovation rather than quantity and cost are the primary performance criteria (Keller, 1992; Mumford, Scott, Gaddis, \& Strange, 2002).

In addition, the moderation-related findings imply that to increase employees' systemic-level justice perceptions and commitment to their organizations, their leader's span of control should be narrowed. In other words, in order to yield positive consequences, organizations may consider creating supportive contexts where leaders are perceived as close by followers. When leaders supervise relatively small numbers of followers, they may be in a better position to build supportive contexts, spend more time with their followers and better communicate the organizational rules and procedures. In such an environment, higher degrees of socialization and a family feeling among the team members can bring about greater commitment to cooperative efforts and collective interests. Furthermore, HR managers should take into consideration that while project leaders enhance organizational commitment only when they supervise low numbers of people, such leaders may create supervisory commitment regardless of their span of control. In other words, transformational leaders with a large span of control may boost supervisory commitment, but not organizational commitment among their team members. This may have some detrimental consequences for followers such as withdrawal cognitions, a low level of job satisfaction (Cheng, Jiang, \& Riley, 2003) and turnover behaviors especially when their leaders leave the company. Hence, if decreasing the direct reports of such a leader is not possible, other mechanisms and tools should be heavily considered to increase organizational commitment. In this regard, policies about compensation, promotion, job design, etc. should be re-visited with employee retention in mind to signal that the organization values their contribution and is committed to them.

In summary, this study examines the mediating effects of justice on the relationship between TL and R\&D workers' commitment to their organizations and leaders in small versus large spans of control. By doing so, this research provides a powerful insight into the central role of TL in developing a just and procedurally fair environment which may foster R\&D workers' commitment.

\section{References}

Antonakis, J., \& Atwater, L. (2002). Leader distance: A review and a proposed theory The Leadership Quarterly, 13, 673-704.

Avolio, B. J. (1999). Full leadership development: Building the vital forces in organizations. Thousand Oaks, CA: Sage.

Avolio, B. J., Bass, B. M., \& Jung, D. I. (1999). Re-examining the components of transformational and transactional leadership using the multifactor leadership questionnaire. Journal of Occupational and Organizational Psychology, 72, 441-463.

Avolio, B. J., Zhu, W., Koh, W., \& Bhatia, P. (2004). Transformational leadership and organizational commitment: Mediating role of psychological empowerment and moderating role of structural distance. Journal of Organizational Behavior, 25 951-968.
Aycan, Z., Kanungo, R. N., Mendonce, M., Kaicheng, Y., \& Deller, J. (2000). Impact of culture on human resource practices: A 10 country comparison. Applied Psychology: An International Review, 49, 192-221.

Bass, B. M. (1990). Bass and Stogdill's handbook of leadership: Theory, research, and managerial applications (3rd ed.). New York: The Free Press.

Bass, B. M. (1995). Transformational leadership. Journal of Management Inquiry, 4, 293-298.

Bass, B. M., \& Avolio, B. J. (1995). MLQ multifactor leadership questionnaire. Redwood City, CA: Mind Garden.

Becker, T. E. (1992). Foci and bases of commitment: Are they distinctions worth making? Academy of Management Journal, 35, 232-244.

Becker, T. E., Billings, R. S., Eveleth, D. M., \& Gilbert, N. L. (1996). Foci and bases of employee commitment: Implications for job performance. Academy of Management Journal, 39, 464-482.

Benson, J., \& Brown, M. (2007). Knowledge workers: What keeps them committed; what turns them away. Work, Employment and Society, 21, 121-141.

Berkman, Ü., \& Özen, Ş. (2007). Turkish business system and managerial culture: State dependency and paternalism in transition. In E. Davel, J. P. Dupuis, \& J. F. Chanlat (Eds.), Culture and management in the contemporary world. Quebec: Laval University.

Berson, Y., Shamir, B., Avolio, B. J., \& Popper, M. (2001). The relationship between vision strength, leadership style, and context. The Leadership Quarterly, 12, 53-73.

Bies, R. J. (2001). Interactional (in)justice: The sacred and the profane. In J. Greenberg, \& R. Cropanzano (Eds.), Advances in organizational justice (pp. 89-118). Stanford, CA: Stanford University Press.

Bies, R. J., \& Moag, J. F. (1986). Interactional justice: Communication criteria of fairness. In R. J. Lewicki, B. H. Sheppard, \& M. H. Bazerman (Eds.), Research on negotiations in organizations, vol. 1. (pp. 43-55)Greenwich, CT: JAI Press.

Bono, J. E., \& Judge, T. A. (2003). Self-concordance at work: Toward understanding the motivational effects of transformational leaders. Academy of Management Journal, $46,554-571$.

Brown, R. B. (1996). Organizational commitment: Clarifying the concept and simplifying the existing construct typology. Journal of Vocational Behavior, 49(3), 230-251.

Cheng, B., Jiang, D., \& Riley, J. H. (2003). Organizational commitment, supervisory commitment, and employee outcomes in the Chinese context: Proximal hypothesis or global hypothesis? Journal of Organizational Behavior, 24, 313-334.

Cohen-Charash, Y., \& Spector, P. E. (2001). The role of justice in organizations: A meta-analysis. Organizational Behavior and Human Decision Processes, 86, 278-321.

Cole, M. S., Bruch, H., \& Shamir, B. (2009). Social distance as a moderator of the effects of transformational leadership: Both neutralizer and enhancer. Human Relations, $62,1697-1733$.

Colquitt, J. A., Conlon, D. E., Wesson, M. J., Porter, C. O. L. H., \& Ng, K. Y. (2001). Justice at the millennium: A meta-analytic review of 25 years of organizational justice research. Journal of Applied Psychology, 86, 425-445.

Conger, J. A., \& Kanungo, R. N. (1998). Charismatic leadership in organizations. London: Sage.

Cropanzano, R., Prehar, C. A., \& Chen, P. Y. (2002). Using social exchange theory to distinguish procedural justice from interactional justice. Group \& Organization Management, 27, 324-351.

Dansereau, F., Graen, G., \& Haga, W. J. (1975). A vertical dyad linkage approach to leadership within formal organizations: A longitudinal investigation of the role making process. Organizational Behavior and Human Performance, 13, 46-78.

Dayan, M., Benedetto, A. D., \& Colak, M. (2009). Managerial trust in new product development projects: Its antecedents and consequences. RED Management, 39, 21-37.

DeConinck, J. B. (2010). The effect of organizational justice, perceived organizational support, and perceived supervisor support on marketing employees' level of trust. Journal of Business Research, 63, 1349-1355.

Despres, C., \& Hiltrop, J. M. (1995). Human resource management in the knowledge age: Current practice and perspectives on the future. Employee Relations, 17, 9-23.

Drucker, P. F. (1969). The age of discontinuity. London: Heinemann.

Drucker, P. F. (1999). Knowledge-worker productivity: The biggest challenge. California Management Review, 41, 79-94.

Felfe, J., Yan, W., \& Six, B. (2008). The impact of individual collectivism on commitment and its influence on organizational citizenship behavior and turnover in three countries. International Journal of Cross Cultural Management, 8, 211-237.

Flood, P. C., Turner, T., Ramamorthy, N., \& Pearson, J. (2001). Causes and consequences of psychological contracts among knowledge workers in the high technology and financial services industries. International Journal of Human Resource Management, $12,1152-1165$

Garcia-Morales, V. J., Jimenez-Barrionuevo, M. M., \& Gutierrez-Gutierrez, L. (2012). Transformational leadership influence on organizational performance through organizational learning and innovation. Journal of Business Research, 65, 1040-1050.

Greenberg, J. (1995). The quest for justice on the job: Essays and experiments. Thousand Oaks, CA: Sage.

Homburg, C., \& Pflesser, C. (2000). A multiple-layer model off market-oriented organizational culture: Measurement issues and performance outcomes. Journal of Marketing Research, 37, 449-462.

Howell, J. M., \& Hall-Merenda, K. E. (1999). The ties that bind: The impact of leadermember exchange, transformational and transactional leadership, and distance on predicting follower performance. Journal of Applied Psychology, 84, 680-694.

Howell, J. M. Neufeld, D. J., \& Avolio, B. J. (2005). Examining the relationship of leadership and physical distance with business unit performance. The Leadership Quarter$l y, 16,273-285$.

Johns, G. (2006). The essential impact of context on organizational behavior. Academy of Management Review, 31, 386-408. 
Jöreskog, K. G., \& Sörbom, D. (1993). LISREL 8: Structural equation modeling with the SIMPLIS command language. Chicago: Scientific Software International.

Judge, T. A., \& Ferris, G. R. (1993). Social context of performance evaluation decisions. Academy of Management Journal, 36, 80-105.

Jung, D. I., \& Avolio, B. J. (2000). Opening the black box: An experimental investigation of the mediating effects of trust and value congruence on transformational and transactional leadership. Journal of Organizational Behavior, 21, 949-964.

Jung, D. I., Bass, B. M., \& Sosik, J. (1995). Bridging leadership and culture: A theoretical consideration of transformational leadership and collectivistic cultures. Journal of Leadership Studies, 2, 3-18.

Jung, D. I., \& Yammarino, F. J. (2001). Perceptions of transformational leadership among Asian Americans and Caucasian Americans: A level of analysis perspective. Journal of Leadership \& Organizational Studies, 8, 3-21.

Karakitapoğlu-Aygün, Z. \& Gumusluoglu, L. (2011). Bright and dark sides of leadership: Transformational leadership vs. non-transformational leadership in a non-Western context. Unpublished manuscript. Bilkent University: Ankara.

Kark, R., Shamir, B., \& Chen, G. (2003). The two faces of transformational leadership: Empowerment and dependency. Journal of Applied Psychology, 88, 246-255.

Keller, R. T. (1992). Transformational leadership and the performance of research and development project groups. Journal of Management, 18, 489-501.

Kim, W. C., \& Mauborgne, R. (1997). Fair process: Managing in the knowledge economy. July-August: Harvard Business Review 65-75.

Kinnear, L., \& Sutherland, M. (2000). Determinants of organizational commitment amongst knowledge workers. South African Journal of Business Management, 31, $106-112$.

Kline, R. B. (1998). Principles and practice of structural equation modeling. New York: Guilford Press.

Lamertz, K. (2002). The social construction of fairness: Social influence and sense making in organizations. Journal of Organizational Behavior, 23, 19-37.

Lavelle, J. J., Rupp, D. E., \& Brockner, J. (2007). Taking a multi-foci approach to the study of justice, social exchange, and citizenship behavior: The target similarity model. Journal of Management, 33, 841-866.

Leventhal, G. S. (1980). What should be done with equity theory? New approaches to the study of fairness in social relationships. In K. Gergen, M. Greenberg, \& R. Willis (Eds.), Social exchange: Advances in theory and research (pp. 27-55). New York: Plenum Press.

Lind, E. A., \& Tyler, T. R. (1988). The social psychology of procedural justice. New York: Plenum Press.

Lowe, K. B., Kroeck, G. K., \& Sivasubramaniam, N. (1996). Effectiveness correlates of transformational and transactional leadership: A meta-analytic review of the MLQ literature. The Leadership Quarterly, 7, 385-425.

Masterson, S. S., Lewis-Mcclear, K., Goldman, B. M., \& Tylor, S. M. (2000). Integrating justice and social exchange: The differing effects of fair procedures and treatment on work relationships. Academy of Management Journal, 43, 738-748.

Meyer, J. P., \& Allen, N. J. (1991). A three-component conceptualization of organizational commitment. Human Resource Management Review, 1, 61-89.

Meyer, J. P., \& Herscovitch, L. (2001). Commitment in the workplace: Toward a general model. Human Resource Management Review, 11, 299-326.

Meyer, J. P., Allen, N. J., \& Smith, C. A. (1993). Commitment to organizations and occupations: Extension and test of a three-component conceptualization. Journal of Applied Psychology, 78, 538-551.

Meyer, J. P., Stanley, D. J., Herscovitch, L. I., \& Topolnytsky, L. (2002). Affective, continuance and normative commitment to the organization: A meta-analysis of antecedents, correlates and consequences. Journal of Vocational Behavior, 61, 20-52.

Moorman, R. H. (1991). Relationship between organizational justice and organizational citizenship behaviors: Do fairness perceptions influence employee citizenship? Journal of Applied Psychology, 76, 845-855.

Morhman, S., Cohen, S., \& Morhman, A. (1995). Designing team-based organizations. San Francisco: Jossey-Bass.

Mowday, R. T., Porter, W., \& Steers, R. M. (1982). Employee-organization linkages: The psychology of commitment, absenteeism and turnover. New York: Academic Press.
Mumford, M. D., Scott, G. M., Gaddis, B., \& Strange, J. M. (2002). Leading creative people: Orchestrating expertise and relationships. The Leadership Quarterly, 13, 705-750.

Napier, B. J., \& Ferris, G. R. (1993). Distance in organizations. Human Resource Management Review, 3, 321-357.

Naumann, S. E., \& Bennett, N. (2000). A case for procedural justice climate: Development and test of a multilevel model. Academy of Management Journal, 43, 881-889.

Pawar, B. S., \& Eastman, K. K. (1997). The nature and implications of contextual influences on transformational leadership: A conceptual examination. Academy of Management Review, 22, 80-109.

Pillai, R., Scandura, T. A., \& Williams, E. A. (1999). Leadership and organizational justice: Similarities and differences across cultures. Journal of International Business Studies, 30, 763-779.

Porter, L. W., \& McLaughlin, G. B. (2006). Leadership and the organizational context: Like the weather? The Leadership Quarterly, 17, 559-576.

Rosenbaum, B. (1991). Leading today's professional. Research-Technology Management $34,30-35$.

Schyns, B., Maslyn, J. M., \& Weibler, J. (2010). Understanding the relationship between span of control and subordinate consensus in leader-member exchange. European Journal of Work and Organizational Psychology, 19, 388-406.

Schyns, B., Paul, T., Mohr, G., \& Blank, H. (2005). Comparing antecedents and consequences of leader-member exchange in a German working context to findings in the US. European Journal of Work and Organizational Psychology, 14, 1-22.

Settoon, R. P., Bennett, N., \& Liden, R. C. (1996). Social exchange in organizations: Perceived organizational support, leader-member exchange, and employee reciprocity. Journal of Applied Psychology, 81, 219-227.

Shamir, B. (1991). The charismatic relationship: Alternative explanations and predictions. The Leadership Quarterly, 2, 81-104.

Shamir, B. (1995). Social distance and charisma: Theoretical notes and an exploratory study. The Leadership Quarterly, 6, 19-47.

Sousa, F. H., \& Vala, J. (2002). Relational justice in organizations: The group-value model and support for change. Social Justice Research, 15, 99-121.

Spector, P., \& Brannick, M. (2010). Methodological urban legends: The misuse of statistical control variables. Organizational Research Methods, 14(2), 287-305.

Thompson, M., \& Heron, P. (2005). The difference a manager can make: Organizational justice and knowledge worker commitment. International Journal of Human Resource Management, 16, 383-404.

Tierney, P., Farmer, S. M., \& Graen, G. B. (1999). An examination of leadership and employee creativity: The relevance of traits and relationships. Personnel Psychology, 52, 591-620.

Trevino, L. K., Brown, M., \& Hartman, L. P. (2003). A qualitative investigation of perceived executive leadership: Perceptions from inside and outside the executive suite. Human Relations, 56, 5-37.

Vandenberghe, C., Bentein, K., \& Stinglhamber, F. (2004). Affective commitment to the organization, supervisor, and work group: Antecedents and outcomes. Journal of Vocational Behavior, 64, 47-71.

Walumbwa, F. O., \& Lawler, J. J. (2003). Building effective organizations: Transformational leadership, collectivist orientation, work-related attitudes, and withdrawal behaviors in three emerging economies. International Journal of Human Resource Management, 14, 1083-1101.

Walumbwa, F. O., Lawler, J. J., \& Avolio, B. J. (2007). Leadership, individual differences and work-related attitudes: A cross-culture investigation. Applied Psychology: An International Review, 56, 212-230.

Walumbwa, F. O., Orwa, B., Wang, P., \& Lawler, J. J. (2005). Transformational leadership, organizational commitment, and job satisfaction: A comparative study of Kenyan and U.S. financial firms. Human Resource Development Quarterly, 16, 235-256.

Walumbwa, F. O., Wang, P., Lawler, J. J., \& Shi, K. (2004). The role of collective efficacy in the relations between transformational leadership and work outcomes. Journal of Occupational and Organizational Psychology, 77, 515-530.

Wasti, S. A. (2000). Cultural and universal predictors of organizational commitment: The case of Turkey. In Z. Aycan (Ed.), Management, leadership and human resources practices in Turkey from the perspectives of academicians and practitioners (pp. 201-224). Ankara: Turkish Psychological Association Press. 